African Crop Science Journal by African Crop Science Society is licensed under a Creative Commons Attribution 3.0 Uganda License. Based on a work at www.ajol.info/ and www.bioline.org.br/cs DOI: http://dx.doi.org/10.4314/acsj.v25i3.7

\title{
GGE BIPLOT APPLICATION FOR ADAPTABILITY OF AFRICAN YAM BEAN GRAIN YIELD TO FOUR AGRO-ECOLOGIES IN NIGERIA
}

\author{
B.D. ADEWALE, D.K. OJO ${ }^{1}$ and M. ABBERTON ${ }^{2}$ \\ Department of Biological Sciences, Ondo State University of Science and Technology, PMB. 353, \\ Okitipupa, Nigeria \\ ${ }^{1}$ International Institute of Tropical Agriculture, Ibadan, Nigeria \\ ${ }^{2}$ Genetic Resources Centre, International Institute of Tropical Agriculture, Ibadan, Nigeria \\ Corresponding author: d.adewale@gmail.com
}

(Received 29 August, 2015; accepted 31 July, 2017)

\begin{abstract}
Genotypes respond to environments differently; therefore it is important that their response to growing environment should be investigated in order to identify most suitable genotype(s) for specific environment. The objective of this study was to understand the adaptability of some accessions of African yam bean to different agro-ecologies of Nigeria. Thirty African yam bean (AYB) (Sphenostylis stenocarpa (Hochst ex. A. Rich) Harms) accessions were evaluated for grain yield adaptability to four agro-environments in Nigeria. Genotype by environment (GE) interaction was significant $(\mathrm{P}<0.01)$ for grain yield, with a range of $239.29 \mathrm{~kg} \mathrm{ha}^{-1}$ (TSs 89) to $4130.46 \mathrm{~kg} \mathrm{ha}^{-1}$ (TSs 33). Two principal component axes generated in the biplots explained $70.9 \%$ of the total variation due to the accessions and their interaction with the environments. The superior genotypes for each location were TSs82 (Ibadan), TSs116 (Mokwa), TSs24 (Ikenne) and TSs33 (Ubiaja). Three mega-environments arose from the study; namely Ikenne, Ubiaja and Mokwa (Ibadan merged with Mokwa to form a single megaenvironment). Ikenne was a more representative environment for AYB production, having a mean grain yield of $1074.53 \mathrm{~kg} \mathrm{ha}^{-1}$, closest to the grand mean of $1075.57 \mathrm{~kg} \mathrm{ha}^{-1}$. However, Ubiaja was most supportive for grain production of AYB. Some of the accessions identified with high yielding, adaptable/stable in the study included TSs101, TSs111, TSs93, TSs94, TSs57, TSs104B and TSs109.
\end{abstract}

Key Words: Accessions, mega-environment, principal components, Sphenostylis stenocarpa

\section{RÉSUMÉ}

Les génotypes répondent différemment aux environnements, donc il importe que leur réponse à l'environnement de production soit investiguée dans le but d'identifier les génotypes appropriés à l'environnement spécifique. L'objectif de cette étude était de comprendre l'adaptabilité de quelques accessions du pois tubéreux africain aux différentes agro-écologies du Nigéria. Trente accessions du pois tubéreux africain (AYB) (Sphenostylis stenocarpa (Hochst ex. A. Rich) Harms) étaient évaluées pour l'adaptabilité du rendement en graines à quatre agroenvironnements au Nigéria. L'interaction du génotype avec l'environnement (GE) était significative ( $\mathrm{P}<0,01)$ pour le rendement en graines, avec une marge de 239,29 $\mathrm{kg} \mathrm{ha}^{-1}$ (TSs 89) à 4130,46 kg ha' (TSs 33). Les deux axes de composantes principales générés dans les biplots, ont expliqué 70,9\% de la variation totale due aux accessions et à leur interaction avec les environnements. Les génotypes supérieurs pour chaque location étaient TSs82 (Ibadan), TSs116 (Mokwa), TSs24 (Ikenne) et TSs33 (Ubiaja). Trois méga-environnements étaient obtenus dans l'étude ; à savoir Ikenne, Ubiaja et Mokwa (Ibadan s'est fusionné avec Mokwa pour former un simple mégaenvironnement). Ikenne était un environnement plus représentatif pour la production de AYB, en ayant un 
rendement moyen en graines de 1074,53 $\mathrm{kg} \mathrm{ha}^{-1}$, proche du plus grand rendement moyen de 1075,57 $\mathrm{kg} \mathrm{ha}^{-1}$. Néanmoins, Ubiaja était plus favorable pour la production en graines de AYB. Les quelques accessions identifiées avec un rendement élevé, adaptable/stable dans cette étude comprennent: TSs101, TSs111, TSs93, TSs94, TSs57, TSs104B et TSs109.

Mots Clés: Accessions, composantes principales, méga-environnement, Sphenostylis stenocarpa

\section{INTRODUCTION}

Genotype-by-environment data from multienvironment trials (METs) are valuable for identifying superior genotypes and evaluating the test environments (Yan and Kang, 2003). Much effort has been made to interpret G x E interaction in multi-environment trial of genotypes (Lin et al., 1986). For every MET variance, components include that of genotypes (G), environment (E) and the interaction of the two. GGE biplot only considers $G$ and GE in a MET data because they are the only sources of variation that are relevant for cultivar evaluation (Gauch and Zobel, 1996; Yan et al., 2000; Yan and Kang, 2003). In typical METs, the $E$ accounts for $\leq 80 \%$ of the total variance; $\mathrm{G}$ and $\mathrm{G} \times \mathrm{E}$ or GE each account for about 10\% (Gauch and Zobel, 1996; Yan et al., 2000; Ortiz et al., 2001).

GGE biplot is a user-friendly software (Yan et al., 2000), working on environment-centre data, which removes the environment main effect and integrates the genotypic main effect with the genotype-by-environment interaction effect of a genotype-by-environment dataset. It displays results of the relationship of the genotypes and the environments in simple, descriptive and explanatory visual graphics. GGE biplot explains the performance of genotypes and the interaction of the same with its environment within a two-dimensional scattered plot based on the scores of the first two principal components (PC) axes (Yan, 2001). Within the GGE biplot the power to discriminate the genotypes is measured by the vector length in the biplot and the representativeness of other test environments is measured by the angle of the test environment with the "average" environment (Yan, 2001).

The visual descriptive statistical tool, according to Yang et al. (2009), has some limitations. GGE biplot software can generate different biplots, depending on the type of scale applied to the data prior to singular value decomposition or principal component analysis (PCA) (Yan and Kang, 2003). Therefore, caution is necessary to avoid indistinct result generation. Miranda et al. (2009) stated that the GGE biplot model diagnosis for MET dataset was useful, but cautioned that the accuracy gained from model diagnosis should not be overstated. The two PC axes, which form the biplot frame do not usually account for the total $(100 \%)$ variability; hence the accuracy of the visual result is relative to the proportion explained by $\mathrm{PC} 1$ and $\mathrm{PC} 2$ of the total variability.

The understanding and the use of the right scale determines the effectiveness and proper interpretation of GGE biplot results (Yan and Kang, 2003). The most commonly used data scaling methods include (a) no scaling, (b) scaling by the standard deviation of genotype means within environments (SD-scaled), and (c) scaling by the standard error within environments (SE-scaled) (Yan et al., 2000). The SE-scaled GGE biplot has been identified as most appropriate for genotype and test environment evaluation because it accounts for heterogeneity among environments in experimental errors (Yan et al., 2000; Yan and Kang 2003; Blanche and Myers, 2006).

The GGE Biplot software has received widespread use by researchers (Naro et al., 2003; Butron et al., 2004; Ma et al., 2004; Kaya et al., 2006; Aremu et al., 2008; Akande and Balogun, 2009; Alake and Ariyo, 2012). 
The multi-facet graphical statistical tool (GGE biplot) informatively explains a higher proportion of the sum of squares of the $\mathrm{GxE}$ interaction with regards to environments and cultivar performance (Namorato et al., 2008; Miranda et al., 2009) and makes visualisation more logical and biological for practice than AMMI (Rao et al., 2011). The objective of this study was to assess the grain yield performance of African yam bean (Sphenostylis stenocarpa (Hochst ex. A. Rich) Harms) accessions evaluated in four distinct agro-ecologies of Nigeria.

\section{MATERIALS AND METHODS}

Thirty accessions of African yam bean, previously reported for genetic variability (Adewale et al., 2012), were evaluated for grain yield in four environments of Nigeria, namely: Ibadan, Ikenne, Mokwa and Ubiaja agroecologies during 2007 growing season. The geographical locations and distinguishing climatic features of the four sites are presented in Table 1. Treatments included thirty accessions of African yam bean and four environments. The experimental design was a randomised complete block (RCB) with three replications. Each replicate had 30 single row plots of 15 metres long and distance between rows was one metre. Three seeds were planted per hill on the ridges at 1 metre apart. The thirty accessions were obtained from the Genetic Resources Centre, International Institute of Tropical Agriculture (IITA), Ibadan, Nigeria.

At planting, a mixture of Premextra and Gramoxone at 80 and $70 \mathrm{ml}$, respectively; in 20 litres of water, was applied to control pre and post-emergent weeds. Thinning of the seedlings was carried out two weeks after planting (WAP), and staking at 3 WAP. Sixty kilogrammes of NPK $(15: 15: 15)$ fertiliser was applied in two splits, by ring application, at 4 and 8 WAP. Insecticide (Nuvacron at $2.5 \mathrm{ml}$
$1^{-1}$ ) was applied at intervals of 2 weeks, from flowering inception to control floral and pod pests. Subsequently, manual weeding was carried out regularly, to keep the field free of weeds.

Grain yield data from the four locations were obtained. Grain yield per hectare $(\mathrm{kg}$ $\mathrm{ha}^{-1}$ ) was calculated as the product of the mean seed yield of 15 plants per plot and 10,000 plants (plant population per hectare). The plot means of grain yield for each replication was subjected to Analysis of Variance (ANOVA) using PROC GLM in SAS for the combined locations. The means of accessions were compared using critical difference (CD), following Singh and Chaudhary (1985):

$\mathrm{CD}=\left(2 \mathrm{MS}_{\mathrm{e}} / \mathrm{r}\right)^{1 / 2} \times \mathrm{t}$

Where:

$\mathrm{Ms}_{\mathrm{e}}=$ the error mean square,

$\mathrm{r} \quad=$ the number of replicates, and

$\mathrm{t}=$ the tabulated value at $5 \%$ level of significance for the degree of freedom of error mean square.

Based on ANOVA, the interaction between the accessions and the environment was significant for grain yield; therefore, the genotype by environment (GE) interaction source of variation was partitioned as recommended by Samonte and Hernandez (1990). The GE variance was partitioned using GGE Biplot Software. Detailed description of the basic model for the GGE biplot was described in Yan (2001) and Yan et al. (2007). From our genotype-by-environment two-way table, different GGE biplots were generated, depending on the scaling factor. In each case, a two-dimensional GGE biplot was constructed with the first two principal components (PC1 and PC2). 
TABLE 1. Coordinates, agro-ecology and total monthly rainfall of the four locations in 2007 cropping season in Nigeria

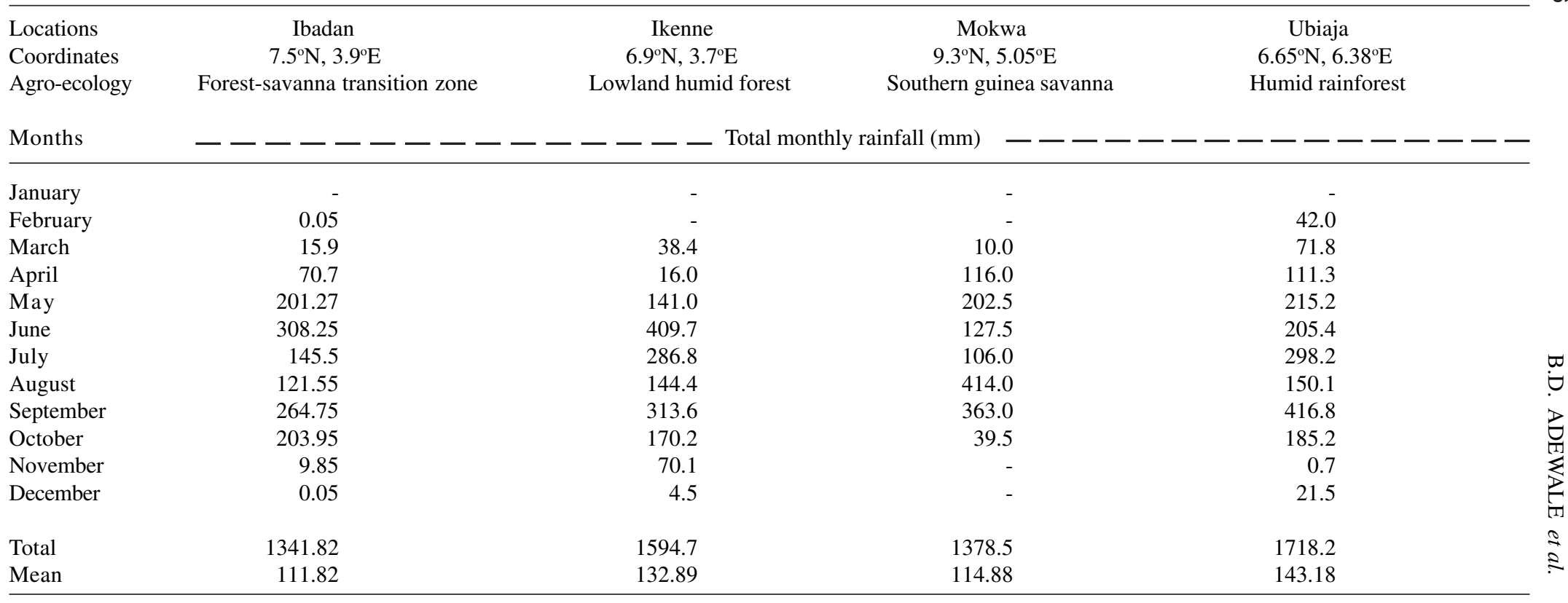

Source: Geo-Spatial Laboratory at IITA, Ibadan, Nigeria 


\section{RESULTS}

There were significant differences $(\mathrm{P}<0.01)$ among the locations, accessions and the interaction of both (Table 2). The highest mean grain yield $\left(2037.74 \mathrm{~kg} \mathrm{ha}^{-1}\right)$ of the thirty accessions was recorded at Ubiaja; followed by Ikenne with a mean of $1074.53 \mathrm{~kg} \mathrm{ha}^{-1}$. The poorest grain yield $\left(440.78 \mathrm{~kg} \mathrm{ha}^{-1}\right)$ was recorded at Mokwa (Table 3). Overall, grain yield ranged between 239.29 (TSs89, Mokwa) to $4130.46 \mathrm{~kg} \mathrm{ha}^{-1}$ (TSs33, Ubiaja).

The GGE biplot for grain yield data of the 30 AYB accessions is presented in Figure 1. The biplot consists of PC1 scores, plotted against PC2 scores for both accessions and environments. The two axes explained $70.9 \%$ of the total variation relative to the accessions and their interaction with the environment (i.e. $\mathrm{G}+\mathrm{GE})$. PC1 scores greater than 0.0 detected the accessions with good adaptability and high yields. Moreover, PC1 with less than 0.0 discriminated the poorly-adapted and low yielding accessions (Fig. 1). Unlike the PC1, PC2 measures genotypic stability or instability. Two groups evolved based on the values $(=0$ or $\neq 0$ ) along the PC2 axis; the stable and the unstable accessions. Accessions found along 0.0 on the PC2 were stable. Accessions farther away from $\mathrm{PC} 2$ at 0.0 were less stable. Therefore, TSs111 was a good and stable yielder; while TSs118 was a poor but stable yielder (Fig. 1).
GGE biplot analysis specifically revealed the performances of the different accessions in each environment (Figs. 2 - 5). The arrowhead thick line in Figures 2 - 5 are the axes of each environment (environmental axis) in the increasing order of accessions yield. In Figures 2 - 5, PL which is perpendicular to each environmental axis separated the thirty accessions differently into two groups: below average (behind the arrow-head) and above average (toward the arrow-head) accessions.

Mean grain yield for the thirty AYB accessions at Ibadan was $749.22 \mathrm{~kg} \mathrm{ha}^{-1}$ (Table 3 ). Accessions with below mean yield (Fig. 2) (featuring at the North of PL) included TSs81, TSs96, TSs109, TSs94, TSs93, TSs23, TSs58, TSs67, TSs118, TSs89, TSs87, TSs48, TSs49 and TSs69. Other accessions to the South of PL (Fig. 2) had higher than mean yield $\left(749.22 \mathrm{k} \mathrm{ha}^{-1}\right)$, TSs 82 ranked top and was the best genotype in Ibadan. TSs 84 had the shortest environmental axis projection in Fig. 2; therefore, it is the most adapted accession in Ibadan.

In Figure 3, sixteen accessions had aboveaverage yield. Mean grain yield at Ikenne was $1074.53 \mathrm{~kg} \mathrm{ha}^{-1}$ (Table 3). TSs24 had the highest yield (about 1.8 tonnes of grain per hectare, Table 3); and was well adapted to the location because of its closeness (short projection) to the environmental axis of Ikenne. TSs 82 trailed behind the fourteen accessions (Fig. 3).

TABLE 2. Summary of the analysis of variance for a grain yield

\begin{tabular}{lcl}
\hline Sources of variation & Degree of freedom & Mean squares \\
\hline Locations & 3 & $43057348.2^{* * * *}$ \\
Accessions & 29 & $570650.4^{* * *}$ \\
Accession x Location & 87 & $349735.8^{* * *}$ \\
Error & 232 & 215360.8 \\
Mean & & 1075.57 \\
CV $(\%)$ & & 43.15 \\
\hline
\end{tabular}


B.D. ADEWALE et al.

TABLE 3. Grain yield $\left(\mathrm{kg} \mathrm{ha}^{-1}\right)$ of the thirty accessions of African yam bean in the four environments in Nigeria

\begin{tabular}{|c|c|c|c|c|c|}
\hline \multirow[t]{2}{*}{ Accessions } & \multicolumn{4}{|c|}{ Environments } & \multirow[t]{2}{*}{ Mean } \\
\hline & Ibadan & Ikenne & Mokwa & Ubiaja & \\
\hline TSs9 & 803.35 & 1036.10 & 374.28 & 1993.69 & 1051.86 \\
\hline TSs 10 & 736.03 & 954.46 & 374.28 & 2819.51 & 1221.07 \\
\hline TSs23 & 661.57 & 1070.96 & 259.88 & 1553.79 & 886.55 \\
\hline TSs24 & 809.93 & 1770.93 & 616.96 & 2780.66 & 1494.62 \\
\hline TSs33 & 946.65 & 1450.97 & 514.48 & 4130.46 & 1760.64 \\
\hline TSs48 & 582.66 & 989.25 & 343.67 & 1505.07 & 855.16 \\
\hline TSs49 & 640.01 & 790.04 & 336.68 & 2028.93 & 948.92 \\
\hline TSs57 & 723.97 & 1267.80 & 629.86 & 2094.04 & 1178.92 \\
\hline TSs58 & 614.46 & 1053.45 & 334.11 & 1197.00 & 799.76 \\
\hline TSs61 & 716.85 & 1168.02 & 449.03 & 1598.66 & 983.14 \\
\hline TSs67 & 441.71 & 1007.96 & 391.16 & 1290.25 & 782.77 \\
\hline TSs69 & 463.00 & 845.90 & 283.05 & 2308.82 & 975.19 \\
\hline TSs81 & 758.91 & 883.13 & 248.00 & 1739.12 & 907.29 \\
\hline TSs 82 & 1471.44 & 784.62 & 429.41 & 1217.61 & 975.77 \\
\hline TSs84 & 1022.05 & 941.37 & 578.59 & 2273.48 & 1203.87 \\
\hline TSs86 & 1425.26 & 1008.32 & 295.43 & 1416.01 & 1036.26 \\
\hline TSs87 & 547.22 & 830.12 & 328.64 & 1303.36 & 752.34 \\
\hline TSs89 & 614.36 & 973.10 & 239.29 & 1920.43 & 936.80 \\
\hline TSs91 & 833.33 & 1022.90 & 331.81 & 1881.42 & 1017.37 \\
\hline TSs93 & 643.10 & 1168.83 & 492.20 & 2062.69 & 1091.71 \\
\hline TSs94 & 513.14 & 1082.82 & 635.79 & 1685.47 & 979.31 \\
\hline TSs95 & 647.76 & 1172.51 & 411.88 & 2071.22 & 1075.84 \\
\hline TSs96 & 586.26 & 1218.06 & 374.38 & 3232.16 & 1352.72 \\
\hline TSs101 & 744.61 & 1157.50 & 471.82 & 1936.31 & 1077.56 \\
\hline TSs104B & 918.06 & 961.49 & 609.79 & 2438.80 & 1232.04 \\
\hline TSs 109 & 590.15 & 1135.60 & 596.09 & 2656.59 & 1244.61 \\
\hline TSs 111 & 783.28 & 1340.52 & 408.42 & 1600.36 & 1033.15 \\
\hline TSs116 & 895.63 & 1291.46 & 1086.91 & 2028.20 & 1325.55 \\
\hline TSs 118 & 478.62 & 796.14 & 462.70 & 1942.27 & 919.93 \\
\hline TSs 125 & 863.35 & 1061.50 & 314.68 & 2425.95 & 1166.37 \\
\hline Mean & 749.22 & 1074.53 & 440.78 & 2037.74 & 1075.57 \\
\hline $\mathrm{CD}(5 \%)$ & 562.09 & 386.12 & 304.19 & 1301.50 & 638.48 \\
\hline $\mathrm{CV}(\%)$ & 46.41 & 22.23 & 42.69 & 39.51 & 37.71 \\
\hline
\end{tabular}

$\mathrm{CD}=$ Critical differences, mean difference between two accessions that exceeds the critical difference value $(\mathrm{CD}$ $(5 \%))$ is significant at $\mathrm{P}=0.05$ 


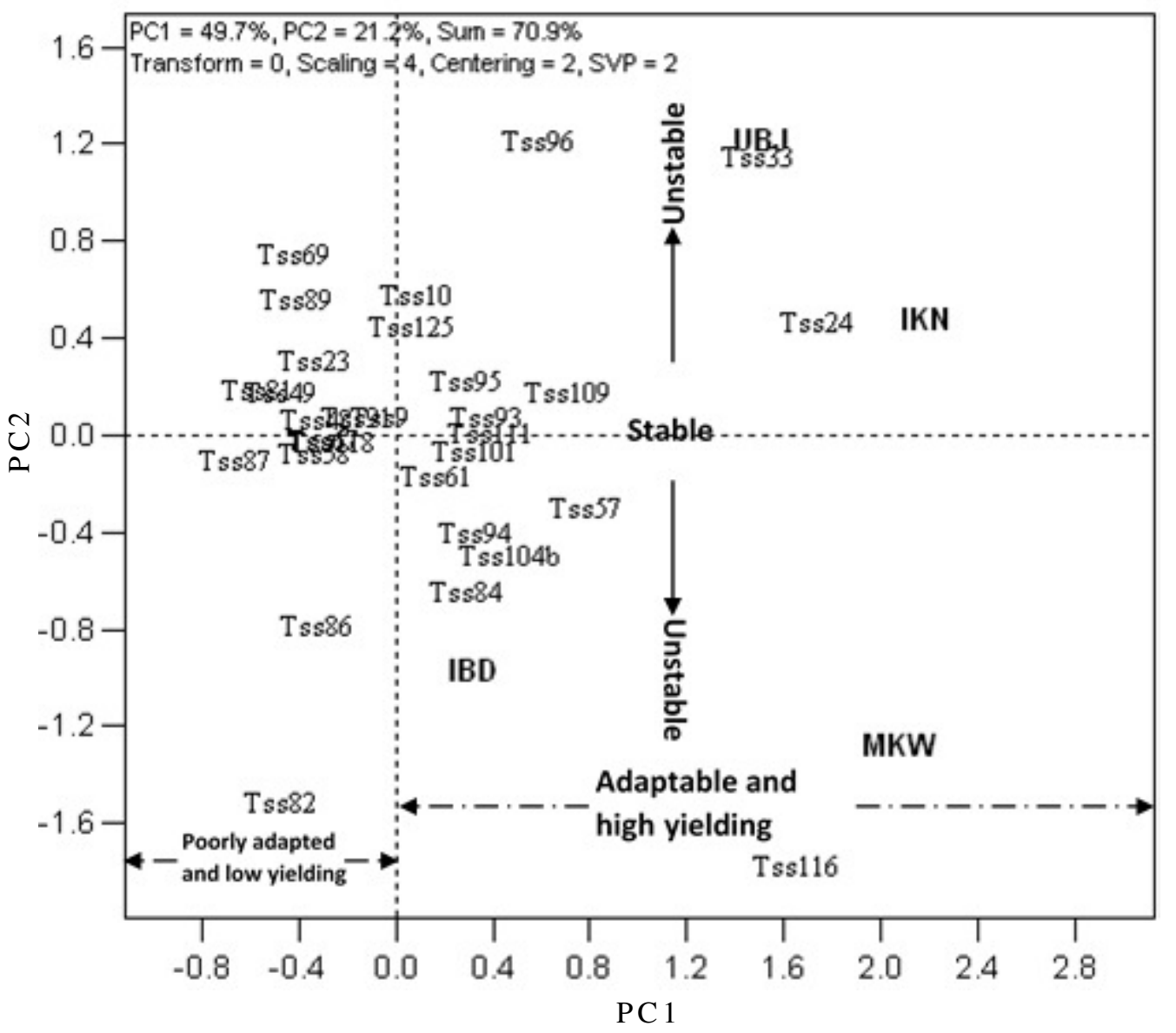

Figure 1. GGE biplot of the grain yield of thirty accessions of African yam bean in a trial across four locations in Nigeria. IBD = Ibadan, IKN = Ikenne, MKW = Mokwa and UBJ = Ubiaja.

In Figure 4, Mokwa environment enhanced the above mean $\left(>440.78 \mathrm{~kg} \mathrm{ha}^{-1}\right)$ performance of 15 accessions. The remaining half of the accessions had grain yield lower than 440.78 $\mathrm{kg} \mathrm{ha}^{-1}$. The higher yielders in Mokwa were to the west of PL. The highest grain yield (1086.91 $\mathrm{kg} \mathrm{ha}^{-1}$, Table 3) was obtained in TSs116. TSs69 was the lowest grain yielder in Mokwa.

Mean yield in Ubiaja was $2037.74 \mathrm{~kg} \mathrm{ha}^{-1}$ (Table 3). Twelve accessions (to the west of PL) had above mean grain yield (Fig. 5). TSs33 had the best performance and was equally the most adapted accession in the agro-ecology because of the proximity of the accession to the environmental axis of the location. TSs82 again trailed behind the remaining 18 poor yielders in Ubiaja.

The polygon view of the GGE biplot gives a visualisation pattern, which reveals the accession that was superior in a specific environment, "which-won-where". Figure 6 presented a GGE biplot, where all the accessions were enclosed within a heptagon. The vertexes were named after the seven accessions at each vertex. Seven projecting lines (OA, OB, OC, OD, OE, OF and OG) from the origin $(\mathrm{O})$, further divided the heptagon into seven sectors, cutting the sides of the heptagon perpendicularly. The four environments fell in three of the seven sectors (Fig. 6). Sector 1 was AOB, which had Ubiaja 


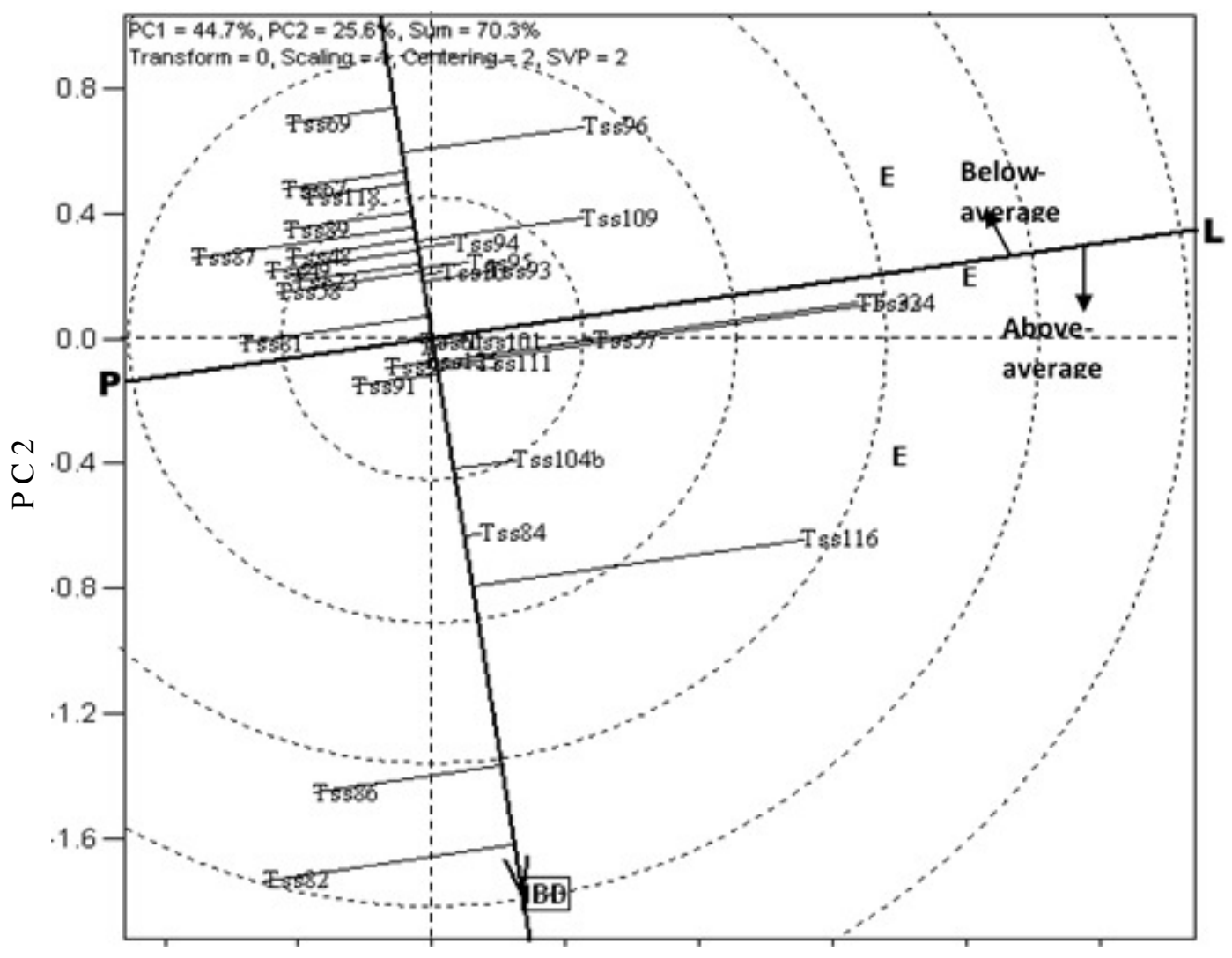

Figure 2. A biplot for grain yield profiles of the thirty accessions of African yam bean at Ibadan, Nigeria.

as the only environment. The two accessions in the sector were TSs33 and TSs96, and both were most adaptable to Ubiaja; but TSs33 (the vertex accession) was superior in grain yield.

BOC was sector 2, in which Ikenne was located. TSs 24 was the vertex accession, and had the highest yield in the environment. Mokwa and Ibadan came under sector 3; TSs116 was the vertex accession with the highest yield. The vertex accessions for sectors 4, 5 and 6 were TSs82, TSs87 and TSs69, respectively. These accessions were unstable; with poor yield and low adaptability with respect to the four tested environments. Sector 7 had no representative accession.

The AEC ordinate and AEC abscissa passed through the origin, and aligned perpendicularly to each other. The AEC ordinate separated the accessions with poor yielders from those with good yielders. Furthermore, the average yield of accessions was approximated by the projections of their markers to the AEC abscissa. Therefore, accessions with good yield, irrespective of their location along the AEC abscissa; included TSs116, TSs96, TSs33, TSs24, TSs95, TSs104B, TSs84 and TSs 109; while those with poor yield were TSs87, TSs82, TSs86, TSs69, TSs89, TSs23, TSs10 (Fig. 7). The AEC abscissa, which passed through the biplot origin and along the average environment, had its arrow head at the spot represented by the small circle. This spot approximated the mean and stable yield of the 30 accessions. It could otherwise be called the ideal AYB accession. TSs57 had the highest proximity to the ideal AYB accession. 


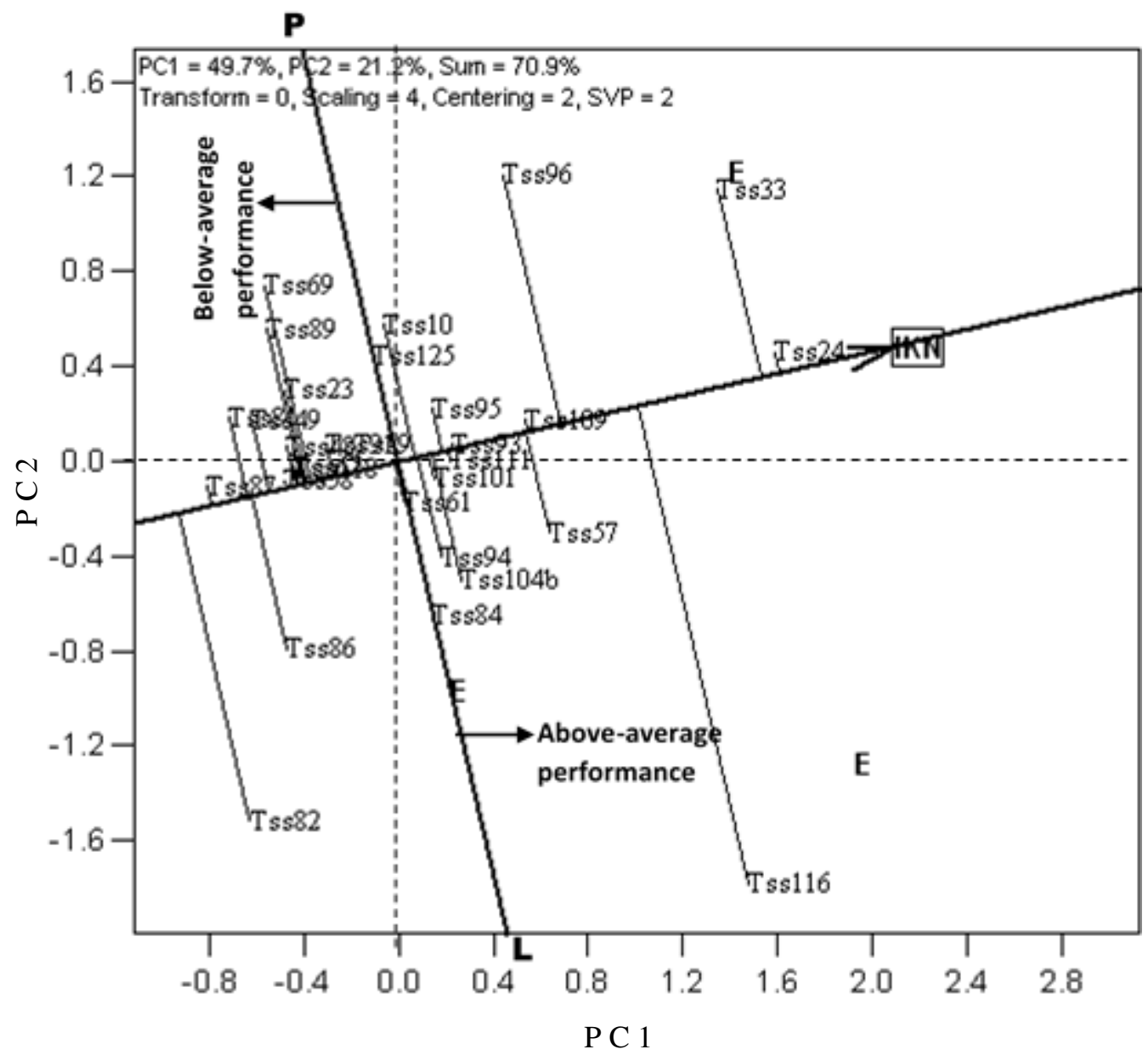

Figure 3. Grain yield performance of the thirty accessions of African yam bean at Ikenne in Nigeria.

Figure 8 displayed the average environment coordinate using the environment-focused scaling in GGE biplot, to test how distinct and representative each environment was. Discriminating ability is based on the vector length of each environment; the longer the more discriminating. A highly discriminating environment provides distinctive information with high genotypic inference on the tested genotypes. Hence, Mokwa, Ikenne and Ubiaja were most discriminating for the thirty AYB accessions than Ibadan. The average environment is indicated by the small circle to which the AEC abscissa axis, passing through the biplot origin, pointed in Figure 8. Therefore, Ikenne was more representative, having a mean grain yield $\left(1074.53 \mathrm{~kg} \mathrm{ha}^{-1}\right)$ closest to the grand mean $\left(1075.57 \mathrm{~kg} \mathrm{ha}^{-1}\right)$. Moreover, Ikenne and Mokwa were near the ideal environment because of the low acute angle of their vector to the AEC abscissa. Ubiaja and Ibadan with larger acute angle to AEC axis were less representative.

\section{DISCUSSION}

The significant differences observed among locations (Table 2) can be attributed to 


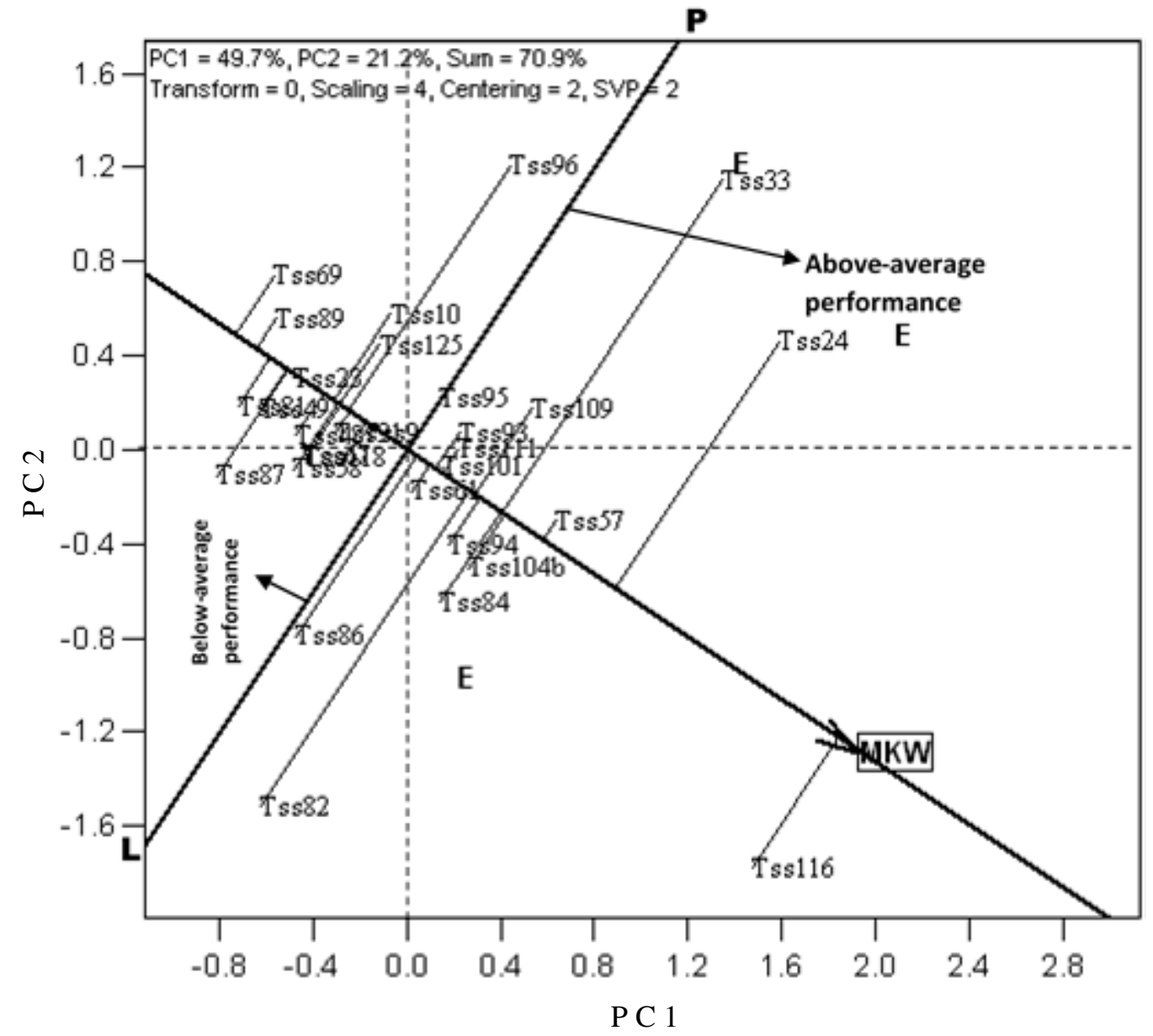

Figure 4. Grain yield performance of the thirty accessions of African yam bean at Mokwa in Nigeria.

differences in rainfall precipitation, with Ibadan having the lowest amount of annual precipitation for the year of study. The wide range in grain yield among the 30 accessions (Table 3) and their significant inconsistent performances in each of the four locations (Table 2) depict the crossover genotype by environment interaction and significant differences among the four environments. The high yields of the thirty accessions in Ubiaja (Table 3) could be linked to the high amount and distribution of rainfall. Lower rainfall as obtained in Mokwa (Southern Guinea Savanna) and Ibadan (Forest-Savanna transition zone) in 2007 may not be supportive to AYB's productivity. Adewale and Odoh (2013) reported that AYB matures within five to seven months. Due to photoperiodic sensitivity, flowering in AYB starts from late September. Hence, the lower yields of the 30 accessions, especially in Mokwa, could be explained by the inadequancy of moisture shortly after flowering. This seems to reflect that moisture availability supports grain filling. Our result concurs with earlier findings (Baigorri et al., 1999; Costa-Franca et al., 2000; GhassemiGolezani et al., 2009) that water deficit during the reproductive growth tends to have the most adverse effect on crop productivity.

Partitioning of the GGE component through GGE biplot analysis (Fig. 1) showed that PC1 and PC2 were the most significant axes, 


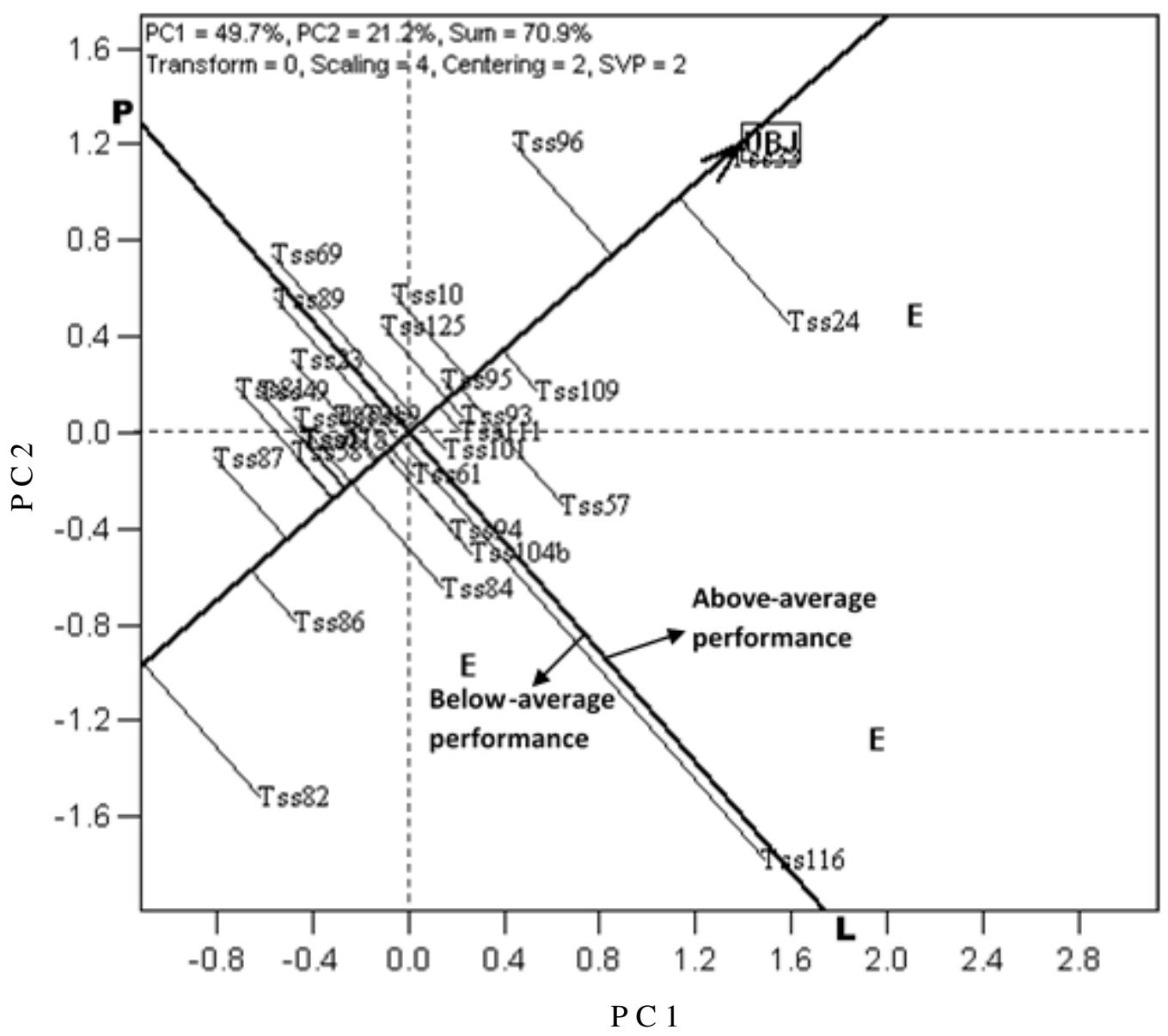

Figure 5. A biplot for grain yield performance of the thirty accessions of African yam bean at Ubiaja in Nigeria.

explaining 49.7 and $21.2 \%$ of GGE sums of squares (GGESS), respectively (Fig. 1). Together, they accounted for $71 \%$ of GGESS. This is a very high proportion of the total variation in the environments and, therefore, the use of GGE biplot to describe genotype performance (Kaya et al., 2006; Aremu et al., 2008) is justified. However, TSs 89 and TSs 58 actually had the lowest yield of 239.29 and $1197 \mathrm{~kg} \mathrm{ha}^{-1}$ in Mokwa and Ubiaja, respectively (Table 3). The biplots in Figures 4 and 5 did not identify them as the lowest yielders in each case. The lower than $100 \%$ (i.e. $70.9 \%$ ) explanation of the total variability by the two
PC axes which generated the two biplots could be implicated for this case.

The stability test of the 30 AYB accessions, using GGE biplot revealed that some were stable and others were not (Fig. 1). Some had good adaptability with high yield and others were poorly adapted and low yielding. TSs 116, TSs24 and TSs33 had high yield and good adaptability at Mokwa, Ikenne and Ubiaja. Although TSs82 had the highest yield in Ibadan, its adaptability status to the same location was poor. The mean grain yield for the 30 accessions was $0.44 \mathrm{t} \mathrm{ha}^{-1}$ (at Mokwa) and $2.04 \mathrm{t} \mathrm{ha}^{-1}$ (at Ubiaja). The agro-ecology 


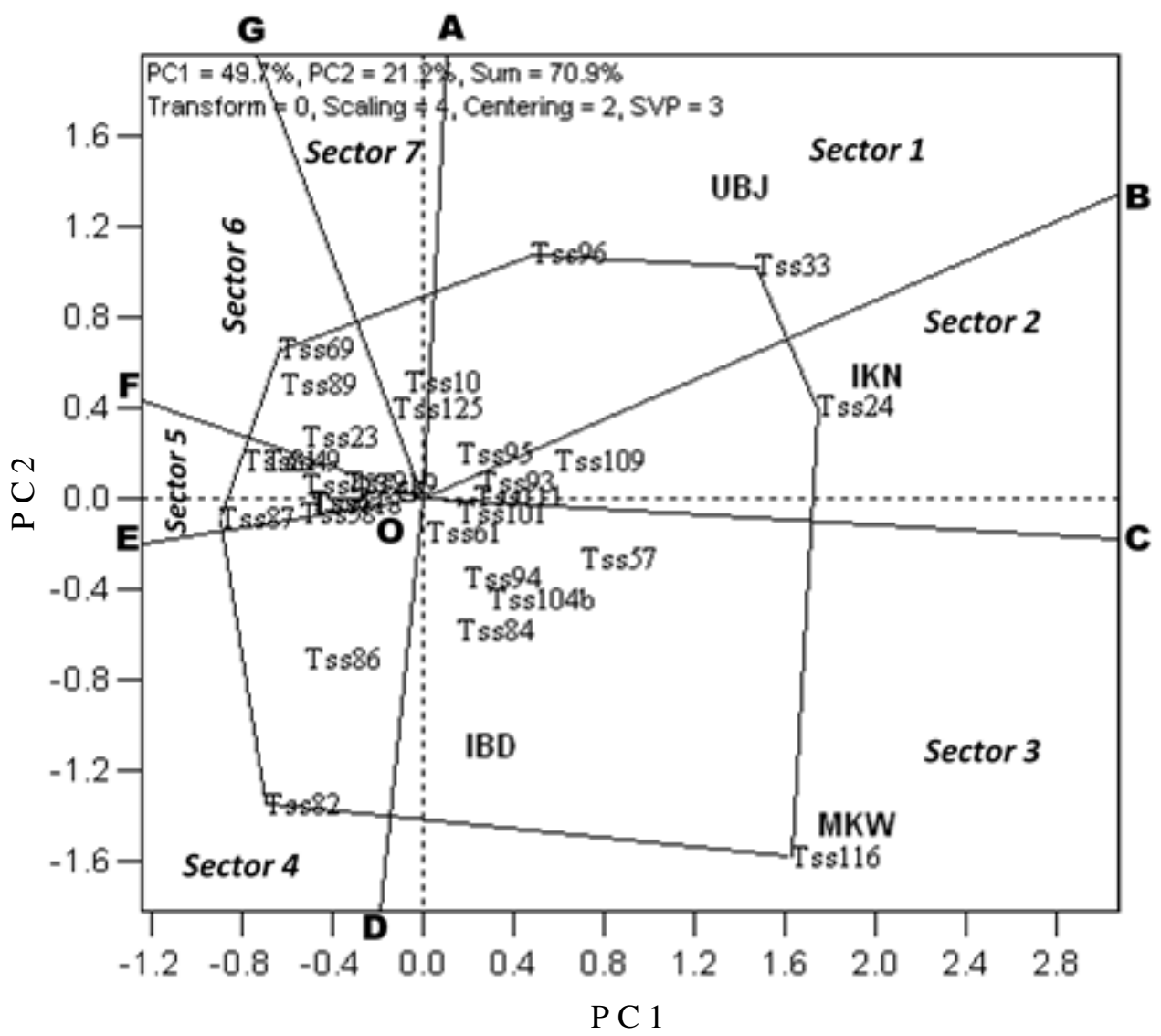

Figure 6. Polygon view of GGE biplot showing which accession had the best grain yield in which environment in Nigeria. IBD - Ibadan, IKN -Ikenne, MKW -Mokwa and UBJ - Ubiaja.

of Ubiaja seems to offer a productive environment for AYB in Nigeria.

The GGE biplot identified three mega environments, namely, Ubiaja, Ikenne and Mokwa for their uniqueness and representativeness in discriminating the thirty accessions of AYB. It, therefore, implied that Ibadan can be classified a microenvironment within Mokwa or vice-versa according to the procedure of Yan et al. (2000); Yan and Kang (2003). Ibadan (forest-savanna transition ecology) and Mokwa (southern guinea savanna ecology) are locations within the Nigerian savanna. Interestingly, the mean annual rainfall for Ibadan in 2007 was lowest (111.82 $\mathrm{mm}$ ) among the other environments and this may have impaired performance of the accessions in Ibadan in 2007. Ikenne and Ubiaja are locations within the forest zone with differing annual rainfalls (Table 1); the differing rainfall could be implicated for the varied performances of the accessions in the two locations.

High PC1 score of an environment makes it highly discriminating among accessions, yet the nearness of the site to zero PC2 scores make it more representative of an average environment (Yan et al., 2001). Ikenne is the nearest to the ideal environment in the present study and, therefore, could be considered to be the most favourable environment for at least an average performance of the 30 tested AYB accessions. Grain yield from Ikenne was $1074.53 \mathrm{~kg} \mathrm{ha}^{-1}$ compared to the overall mean 


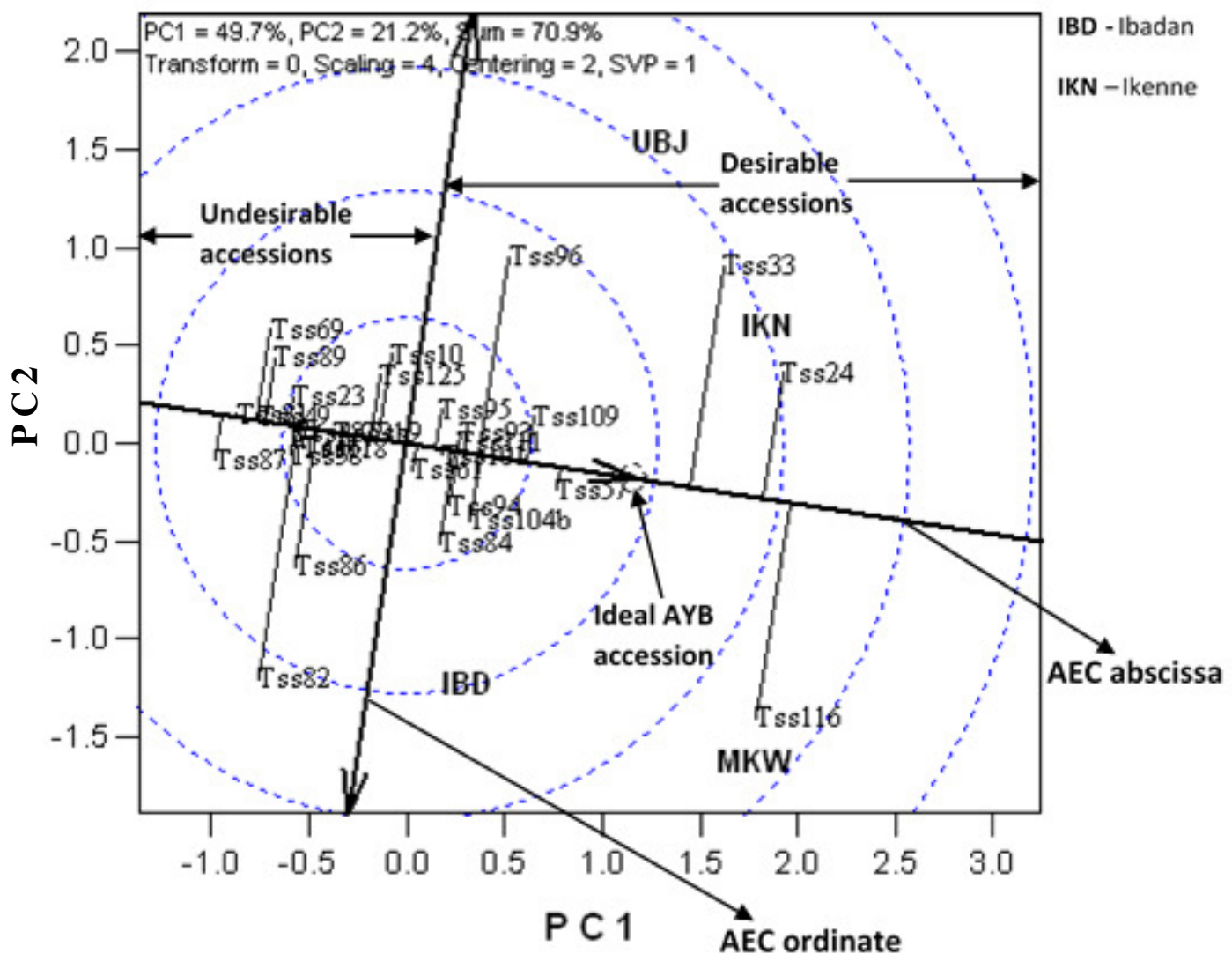

Figure 7. Mean environment coordinates (AEC) view of the GGE biplot based on the accession-focused scaling, showing the mean yield and stability of accessions. IBD - Ibadan, IKN -Ikenne, MKW -Mokwa and UBJ Ubiaja.

grain yield of $1075.57 \mathrm{~kg} \mathrm{ha}^{-1}$. The present study did not identify Ibadan as a megaenvironment; however, further studies with many years' data (Yan and Kang, 2003) would be needed to authenticate the relevance of Ibadan as a testing site for AYB evaluation in Nigeria.

\section{ACKNOWLEGEMENT}

The first author wishes to acknowledge the partnership and the technical support of Mr. Adekunle Akinyemi and Mr. David Ogunsola (Genetic Resources Centre, International Institute of Tropical Agriculture, Ibadan) during the period of his doctoral study in the four locations.

\section{REFERENCES}

Adewale, B.D., Aremu, C.O. and Amazue, U.E. 2012. Intra-specific variability and diversity of African yam bean by seed size parameters. Journal of Agricultural and Biological Science 7:454-461.

Adewale, B.D. and Odoh, N.C. 2013. A review on Genetic resources, diversity and agronomy of African yam bean (Sphenostylis stenocarpa (Hochst. ex A. Rich.) Harms): A potential future food crop. Sustainable Agriculture Research 2:32-43

Akande, S.R. and Balogun, M.O. 2009. Multilocational evaluation of Cowpea grain yield and other reproductive characters in the forest and southern Guinea Savanna 


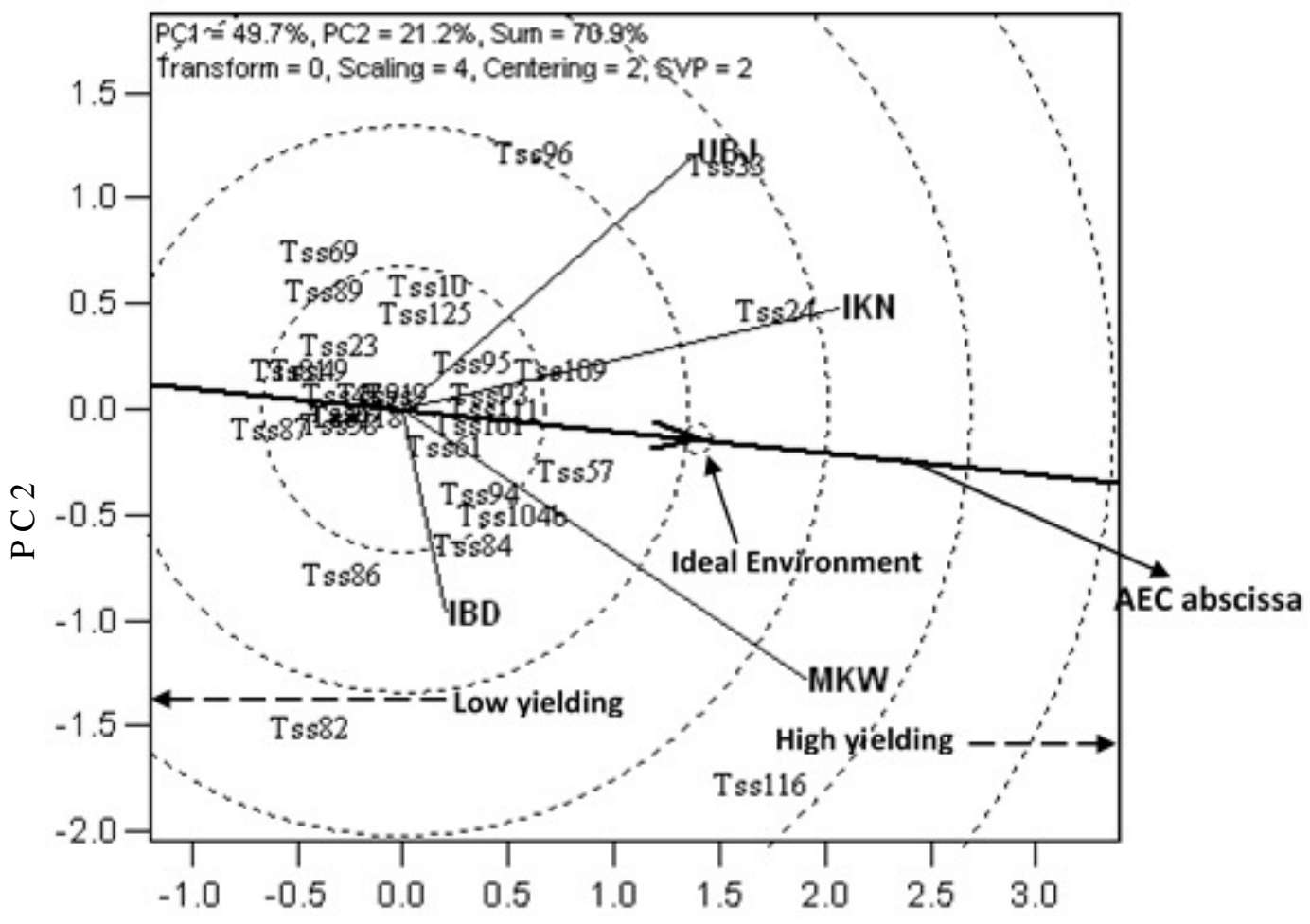

Figure 8. Mean environment coordinates (AEC) piew of the GGE biplot based on the environment-focused scaling, showing the ideal environment for AYB along the AEC abscissa. IBD = Ibadan, IKN = Ikenne, MKW = Mokwa and UBJ = Ubiaja.

agroecologies of Nigeria. Electronic Journal of Environment, Agriculture and Food Chemistry 8:526-533.

Alake, C.O. and Ariyo, O.J. 2012. Comparative Analysis of Genotype $\mathrm{x}$ Environment Interaction Techniques in West African Okra, (Abelmoschus caillei, A. Chev Stevels). Journal of Agricultural Science 4:135-150.

Aremu, C. O., Adebayo, M. A. and Adeniji, O. T. 2008. Seasonal performance of cowpea (Vigna unguiculata) in humid tropics using GGE biplot analysis. World Journal of Biological Research 001:8-13.

Baigorri, H., Antolini, M.C. and Sanchez-Diaz, M. 1999. Reproductive response of two morphologically different pea cultivars to drought. European Journal of Agronomy 10:119-128.

Blanche, S.B. and Myers, G.O. 2006. Identifying discriminating locations for cultivar selection in Louisiana. Crop Science 46: 946-949.

Butron, A., Velasco, P., Ordas, A., and Malvar, R. A. 2004. Yield evaluation of maize cultivars across environments with different levels of pink stem borer infestation. Crop Science 44:741-747.

Costa-Franca, M.G., Thi, A.T., Pimental, C., Pereyra, R.O., Zuily- Fodil, Y. and Laffray, D. 2000. Differences in growth and water relations among Phaseolus vulgaris cultivars in response to induced drought stress. Environ. Experimental Botany 43:227-237. 
Gauch, H.G. and Zobel, R.W. 1996. AMMI Analysis of yield trials: In: Kang, M.S. and Gauch, H.G. (Eds.) Genotype-byEnvironment Interaction. CRC Press, Boca Raton, Florida, USA. 122pp.

Ghassemi-Golezani, K. Ghanehpoor, S. and Mohammadi-Nasab, A.D. 2009. Effects of water limitation on growth and grain filling of faba bean cultivars. Journal of Food, Agriculture and Environment 7: 442447.

Kaya, Y., Akcura, M. and Taner, S. 2006. GGE-Biplot Analysis of Multi-Environment Yield Trials in Bread Wheat. Turkey Journal of Agriculture and Forestry 30: 325-337

Ma, B.L., Yan, W., Dwyer, L.M., Fregeau-Reid, J., Voldeng, H.D., Dion, Y. and Nass, H. 2004. Graphic analysis of genotype, environment, Nitrogen fertilizer, and their interaction on spring wheat yield. Agronomy Journal 96: 169 - 180.

Miranda, G.V., de Souza, L.V., Guimarães, L.J.M., Namorato, H., Oliveira, L.R. and Soares, M.O. 2009. Multivariate analyses of genotype $\mathrm{x}$ environment interaction of popcorn. Pesquisa Agropecuária Brasileira 44: 45-50.

Namorato, H., Miranda, G.V., de Souza, L.V., Oliveira, L.R. DeLima, R.O. and Mantovani, E.E. 2008. Comparing Biplot Multivariate Analyses with Eberhart and Russell' method for genotype $\mathrm{x}$ environment interaction. Crop Breeding and Applied Biotechnology 9: 299-307.

Naro, L., Pandey, S., Crossa, J., DeLeon, C. and Salazar, F. 2003. Using Line X Tester interaction for the formation of yellow maize synthetics tolerant to acid soils. Crop Science 43: 1718 - 1728.

Ortiz, R., Wagoire, W.W., Hill, J., Chandra, S., Madsen, S. and Stølen, O. 2001. Heritability of and correlations among genotype-by-environment stability statistics for grain yield in bread wheat. Theoretical and Applied Genetics 103:469-474.
Rao, P.S., Reddy, P.S., Rathore, A., Reddy, B.V.S. and Panwar, S. 2011. Application GGE biplot and AMMI model to evaluate sweet sorghum (Sorghum bicolor) hybrids for genotype $\times$ environment interaction and seasonal adaptation. Indian Journal of Agricultural Sciences 81: 438-444.

Samonte, S.O. and Hernandez, J.E. 1990. Genotype x Environment interaction of irrigated lowland rice variance components and optimum allocation of resources. Philippine Journal of Crop Science 14: 5566.

Singh, R.K. and Chaudhary, S.D. 1985. Biometrical methods in quantitative genetic analysis. Kalyan Publishers, New Delhi, India. 214pp.

Yan, W., Hunt, L.A., Sheng, Q. and Szlavnics, Z. 2000. Cultivar evaluation and mega environment investigation based on the GGE biplot. Crop Science 40: 597-605.

Yan, W. 2001. GGE biplot - A window application for graphical analysis of multi environment trial data and other types of two-way data. Agronomy Journal 93: 11111118.

Yan, W., Cornelius, P.L., Crossa J. and Hunt, L.A. 2001. Two types of GGE biplots for analyzing multi-environment trial data. Crop Science 41: 656-663.

Yan, W. and Kang, M.S. 2003. GGE Biplot Analysis: A graphical tool for breeders, geneticists and Agronomists, CRC Press, Florida, USA. 271pp.

Yan, W., Kang, M.S., Ma, B., Woods, S. and Cornelius, P.L. 2007. GGE Biplot vs. AMMI Analysis of Genotype-byEnvironment Data. Crop Science 47:641653.

Yang, R.-C., Crossa, J., Cornelius, P.L. and Burgueno, J. 2009. Biplot analysis of Genotype $\times$ Environment interaction: Proceed with Caution. Crop Science 49:1564 - 1576. 